\title{
Functional Design of Eccentric Adjusting Mechanism of Heat Insulation Pipe
}

\author{
Jing Shu \\ ${ }^{1}$ Southwest Petroleum University, School of Mechanical and Electrical Engineering, \\ No. 8 Road, Xindu District of Chengdu City, Sichuan province, China
}

\begin{abstract}
With the rapid development of science and technology of industrial production, the continuous emergence of new branches, the impact of the traditional mechanical design methods, means, and the supplement and perfect, modern design method has leapt to a new level. The thermal insulation pipe eccentric adjustment in the production process of actuator design process as an example, the application of modern design idea of, a systematic approach to the design of conceptual design, the modern design theory has been practiced and tested in the manufacturing industry, to develop our design ideas.
\end{abstract}

Keywords: Adjusting mechanism; Functional Design; Heat Insulation Pipe

\section{Introduction}

With the rapid development of petroleum industry, thermal insulation pipe production line put forward newer and higher requirements to the mechanical product, the old machinery products gradually exposed its own cannot overcome the defects, so that the production of thermal insulation pipe quality often do not meet the requirements.

No objective need, there will be no task design. Design comes to the objective needs, and to meet this demand as a result. Mechanical design task is according to the objective demand, through creative people's thinking activity, with mankind has mastered a variety of information resources after repeated judgment and decision making, design technology device with specific functions, the system is products to meet the needs of the growing life and production.

Overall design the first thing to consider global issues. Its mission is to meet the requirement of the function of mechanical system, and expand the scope of system design. The overall design should deal with not only in order to catch up with and surpass the advanced level, but also accord with the law of the land, it is necessary to have advanced technology, but also economically reasonable, both to be easy to manufacture, but also the use of maintenance is convenient wait for a relationship[1].

We developed products, will be for the production of the field. On the basis of the original production machinery, through the improvement, innovation, the modeling process, put forward newer and more perfect theory of the scheme in order to use requirement and improve the economic benefits of the.

\section{Principle of Functional Analysis}

General mechanical product has certain complexity, to design a can meet the functional requirements of the machine is more difficult. Functional analysis is the overall function of mechanical product way function tree decomposition is divided into function, and then broken down into a number of simple function element, function element method, then the combination [2], can often be obtained by mechanical product scheme multiple solutions, and relative optimum solution is obtained.

Analysis of the general function of the often used "black box", to seize the essence of reasonable abstraction and decomposition of the total function is for the final solution, the functional element is the smallest unit of solving. Function tree of function is the function of objective function, function is pre function by means of function. Through relatively simple function element method to solve the problem of the solution of a general function. Below with multi degree of freedom moving mechanism as an example of using the function analysis method were analyzed.

\section{The functional analysis and draw the map of the black box}

3.1 General function: the center of the center of the tube and the center of the heat preservation tube is adjusted.

\subsection{Functional analysis}

\section{(1)The main function}

- Lateral movement of heat preservation pipe case

- Longitudinal movement of heat preservation pipe case

- The transverse, longitudinal and simultaneous movement of the outer casing of the heat preservation pipe

(2)The auxiliary function

- The whole device can move forward and backward.

- The adjusting ring can have switching mechanism

- Support function of support the functional unit

(3)The power supply energy

- Coupling the output of the motor rotating directly to the rotation of the screw

- The rotating motion is converted into a linear reciprocating motion. 


\section{International Journal of Science and Research (IJSR) \\ ISSN (Online): 2319-7064 \\ Index Copernicus Value (2013): 6.14 | Impact Factor (2015): 6.391}

3.3 The holding tube eccentric adjustment mechanism of the black box description

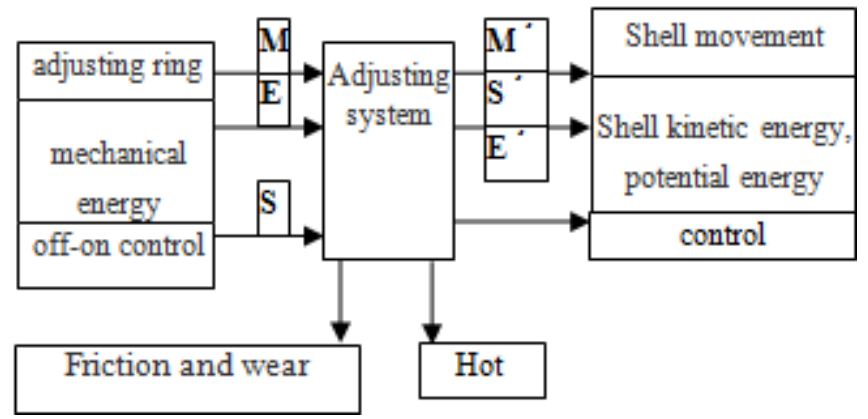

In the analysis of the geometric model of, the establishment of the top-down approach and combined with the overlap operation to complete.

\subsection{Function structure diagram}

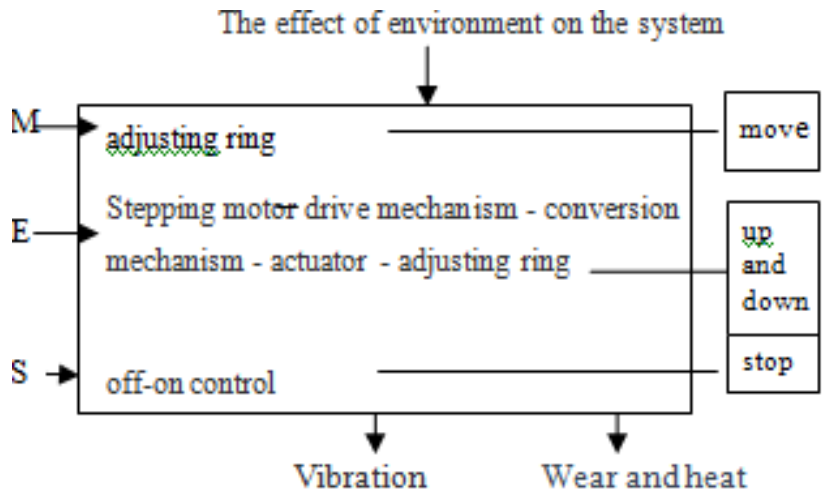

\section{Functional Principle Implementation}

A. The morphological matrix of the function of the thermal insulation pipe adjustment mechanism

\begin{tabular}{|c|c|c|c|c|}
\hline $\begin{array}{c}\text { A. power } \\
\text { supply }\end{array}$ & $\begin{array}{c}\text { D-c } \\
\text { generator }\end{array}$ & Gasoline engine & $\begin{array}{c}\text { Diesel } \\
\text { engine }\end{array}$ & $\begin{array}{c}\text { Stepping } \\
\text { motor }\end{array}$ \\
\hline $\begin{array}{c}\text { B. } \\
\text { transmission } \\
\text { gear }\end{array}$ & Belt drive & Gear drive & $\begin{array}{c}\text { Worm } \\
\text { drive }\end{array}$ & $\begin{array}{c}\text { Pulley } \\
\text { speed } \\
\text { reducing } \\
\text { mechanism }\end{array}$ \\
\hline $\begin{array}{c}\text { C. Motion } \\
\text { conversion } \\
\text { mechanism }\end{array}$ & $\begin{array}{c}\text { Slide block } \\
\text { mechanism }\end{array}$ & $\begin{array}{c}\text { Screw } \\
\text { mechanism }\end{array}$ & Windlass & Roller type \\
\hline $\begin{array}{c}\text { D. } \\
\text { Enforcement } \\
\text { agencies }\end{array}$ & $\begin{array}{c}\text { Integral } \\
\text { adjusting } \\
\text { ring }\end{array}$ & $\begin{array}{c}\text { With the opening } \\
\text { and closing } \\
\text { mechanism } \\
\text { adjusting ring }\end{array}$ & $\begin{array}{c}\text { Assembled } \\
\text { adjusting } \\
\text { ring }\end{array}$ & \\
\hline
\end{tabular}

Total number of programs: $\mathrm{N}=4 * 4 * 4 * 3=192$ species

\section{B. Scheme evaluation}

1. The evaluation of power source:

The series motor has become the standard, and the price is cheap, the choice of power source only needs to check the manual can, convenient motor selection, as applicable. Diesel engine, gasoline engine need energy consumption, pollution is more serious, and big noise, DC motor is not easy to control, but the stepper motor has the advantages of small volume, easy to control, and has the advantages of compact structure and light in weight.

\section{Evaluation of transmission mechanism:}

Worm and worm gear deceleration is relatively large, but at high speed, friction wear large, easy to heat, is not conducive to long-term work. But it will transform the rotation into linear motion. Belt mechanism reduction ratio, simple structure, small volume, light weight, high efficiency. But the equiangular speed output mechanism of complex structure, force. Gear reduction gear transmission ratio accurate, high transmission efficiency, suitable for a wide range of power and speed, compact structure, reliable work, long life, good compatibility, widely used in petroleum machinery [3].

\section{Motion conversion mechanism evaluation:}

Slide block mechanism only for linear motion between the conversion, and big friction; screw mechanism to the motor rotation into linear motion for the adjustment ring, to meet the functional requirements, and the utility model has the advantages of simple structure, cheap. It is easy to realize the long stroke, but the service life of the flexible parts and the reliability of the reversing mechanism are the key problems in the development.

\section{The implementation of institutional evaluation:}

Integral type can only be part of the adjustment to a diameter of the insulation pipe of eccentric adjusting, inconvenient disassembly, versatility, opening and closing type of the adjusting ring can according to different diameter pipe insulation adjustment, strong universality, non removable; assembly type adjusting ring installed disassembly is troublesome, low work efficiency drop. Integrated above the advantages and disadvantages of the functional unit structure, taking into account the main purpose of this course is to play creative thinking, design in the past no or innovative products, so the adoption of the following three programs. Plan 1: DC motor - with the drive - screw - the implementation of the system. Project two: stepping motor - worm gear - screw - the implementation of the system Scheme three: stepping motor, worm gear, sliding slider - Execution System .The following will be a detailed description of the third programs[4]. According to the above method, the insulation tube eccentric mechanism is shown in Figure 1.

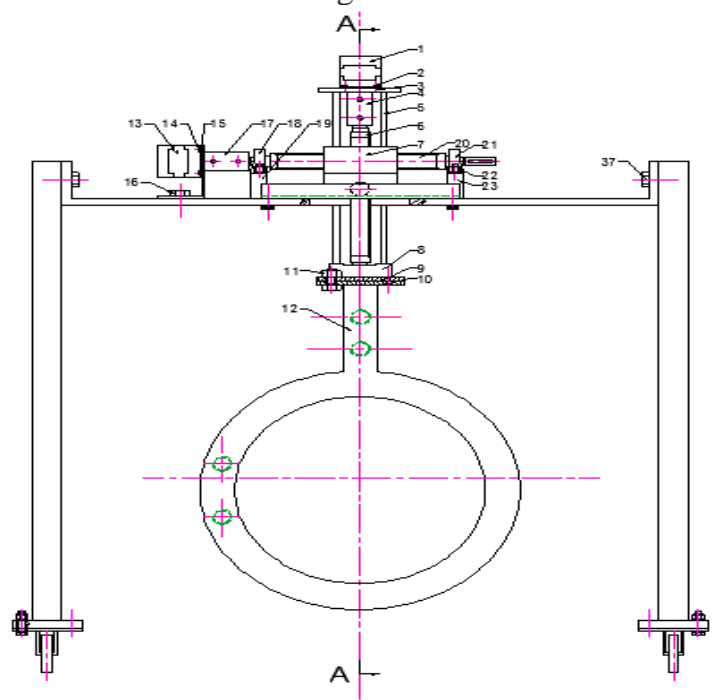

Figure 1: Eccentric mechanism of thermal insulation pipe

\section{Volume 5 Issue 8, August 2016}


Insulation pipe eccentric adjustment device, it can be achieved on the left, right, under the direction of four distance regulation. The technical scheme: the power system of the device with a step motor; driving system with the adjusting screw on the adjusting screw, around, around the adjusting screw through adjust the car lateral screw hole, both ends of the fixed bearing with the rolling, with the vertical thread adjusting screw and adjusting carriage holes on both sides of the two axis parallel fixed on the adjusting screw, the lower upper and lower adjusting screw with rolling bearings mounted in the bearing base of rolling bearings, bearing base welding ring connecting plate in adjustment, and adjust the ring plate with bolts. Rail car placed in parallel on both sides of the fixed screw. The stepper motor rotates to drive the screw rotation, screw rotation into linear motion around the car and adjust the adjusting ring of the rectilinear motion, in order to achieve insulation pipe The center of the protective layer of the yellow jacket is adjusted by the center of the center of the steel tube in the center of the center of the tube in the upper and lower four directions.

\section{Conclusion}

The design requirements of the insulation tube eccentric adjusting mechanism is mainly for the insulation pipe external thermal insulation layer caused by uneven heat pipe effect is poor and the holding tube of eccentric adjusting, so design considering control precision, function needs, chose the third option, and the structure design. Scheme design can meet the insulation pipe shell multi direction eccentric adjusting and regulating precision up to $0.01 \mathrm{~mm}$.

\section{References}

[1] Tang Yanqing. The development and application of the technology of thermal insulation pipe pre fabrication and forming process $[\mathrm{J}]$. petroleum engineering construction, 2012.12.10-12.

[2] Zhang Jingyuan. Automatic deviation correction control system for the production line of foam jacket of the "one step" $[\mathrm{J}]$. petroleum engineering construction, 1998.2.34-37.

[3] Ma Ming, Wu Bin, Guang Cun Wei, Hao Aixin. A. Control of large diameter pipeline anticorrosion insulation "one-step" operation eccentricity approach [J]. Petroleum engineering construction, 2009.35 (5).33-35

[4] Wen Bang spring. The mechanical design manual [M]. Beijing: Mechanical Industry Press, 2010.109-111

\section{Author Profile}

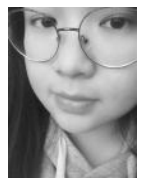

Jing Shu received the College of mechanical and electrical engineering, Southwest Petroleum University, bachelor's degree, master's degree in reading, the main research direction for nondestructive testing, electromagnetic field simulation. 